\title{
COMPOSITE EFFECT OF STUB SQUARE STEEL TUBED COLUMNS UNDER AXIAL COMPRESSION
}

\author{
X. H. Zhou ${ }^{1}$, D. Gan ${ }^{1,2 *}$, J. P. Liu ${ }^{1}$ and Y. F. Chen ${ }^{3}$ \\ ${ }^{1}$ Key Laboratory of New Technology for Construction of Cities in Mountain Area (Chongqing University), \\ Ministry of Education, Chongqing 400045, China \\ ${ }^{2}$ School of Civil Engineering, Chang'an University, Xi'an 710061, China \\ ${ }^{3}$ Department of Civil Engineering, The Pennsylvania State University, Middletown, PA 17057, USA \\ *(Corresponding author: E-mail: gandan@cqu.edu.cn)
}

Received: 28 January 2016; Revised: 16 December 2016; Accepted: 27 December 2017

\begin{abstract}
The in-filled concrete of square tube confined concrete columns (tubed columns for short) is non-uniformly confined and the effectiveness of its confinement is reduced, leading to a complex composite effect. This paper discusses key parameters, including friction, width-to-thickness ratio and chamfered corner radius of steel tubes, which would affect the confinement of square tubes on in-filled concrete. Eighteen specimens with large width-to-thickness ratio and six RC counterparts were tested under axial compression. Four main system parameters were considered in the tests: 1) width-to-thickness ratio $(60-160) ; 2)$ types of steel tubes (galvanized and ordinary); 3 ) interface between tube and concrete (reduced friction and not); and 4) with and without reinforcement cage. It was found that the square tubed RC and plain RC columns were characterized by the shear failure mode, but the ductility performance of the tubed columns was much better than the RC specimens. The axial load-carrying capacities of the specimens with smaller friction were slightly lower than those with larger friction. A finite element analysis (FEA) model was developed to analyze the influence of friction and corner radius on of square tubed columns. An effective section confining model considering effective utilization index of square steel tubes was developed to predict the axial load resistances. The results are satisfactory when comparing the predictions to the experimental and nonlinear finite element analysis results.
\end{abstract}

Keywords: Square steel tubed column, concrete-filled tube column, composite effect, friction coefficient, effective utilization index, axial load-carrying capacities

DOI: $10.18057 / \mathrm{IJASC} .2018 .4 .2 .8$

\section{INTRODUCTION}

Steel and composite structures composed of steel, concrete and composite members are widely used to-date due to their structural efficiency and economy, especially in mid- and high-rise buildings[1-2]. The square tube confined concrete column (tubed column for short) is a special concrete-filled tube (CFT) column, in which the outer thin-walled square tube does not pass through the beam-column joint to avoid direct axial loading. The longitudinal stress of steel tubes mainly comes from the bond and friction between concrete and steel tube. In order to sustain tensile force and flexural moments, reinforcement cage or steel sections embedded in concrete are also needed in tubed columns in practice (Liu et al. [3]). Such structures are referred as "square tubed reinforced concrete (STRC) columns" (Figure 1a) or "square tubed steel reinforced concrete (STSRC) columns" (Figure 1b). The use of external tube to confine concrete has become popular in retrofitting concrete structures. In recent years, the research group in Chongqing University makes great efforts to apply tubed columns and their structural systems to newly built buildings and bridges. A connection system, connecting circular tubed reinforced concrete columns to RC beams, was proposed by the authors. The joint system showed superior structural behavior when subjected to axial compression and cyclic testing. (Gan et al. [4]). 


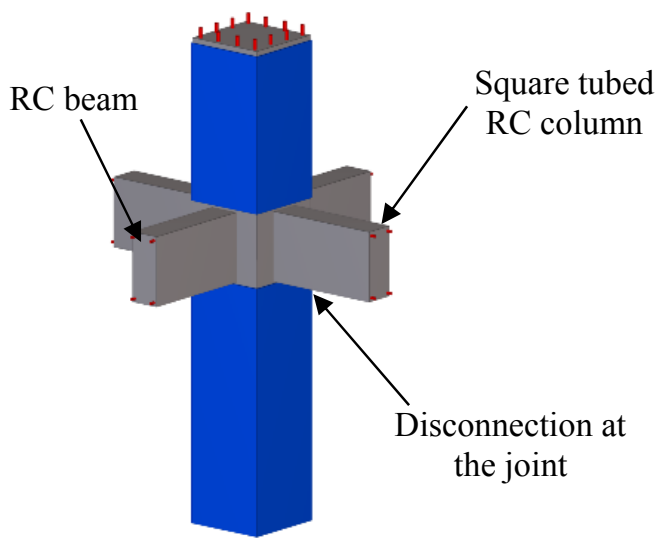

(a) Square tubed RC column

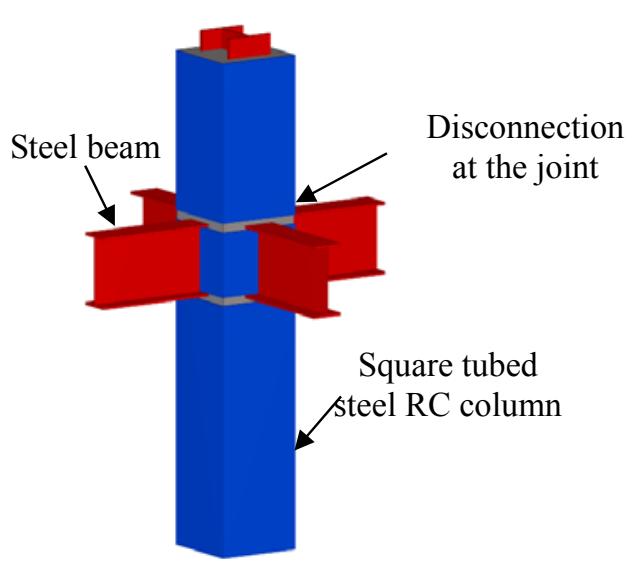

(b) Square tubed steel RC column

Figure 1. Square Tubed Columns

Steel tube confines concrete and hence increases the strength and ductility of concrete columns. Many researches have been devoted to the behavior of circular CFT columns, circular tubed columns, and circular tubed columns using oil or other materials to reduce friction coefficient under axial compression (Sakino et al. [5], Orito et al. [6], Fam et al. [7], Han et al. [8], and Liu et al. [9]). The ductility performance of the circular composite columns tested above was fairly good. Test results also have shown that the axial load capacities of circular tubed columns with reduced friction were slightly higher than those of the conventional tubed columns and that the axial load capacities of both types of tubed columns were higher than those of CFT columns. However, circular tubed columns with reduced friction had the lowest stiffness.

Sakino et al. [10-11] investigated the behavior of square tubed plain concrete columns with reduced friction under axial compression. Their tests results showed that the square tube could provide enough confinement effect when the width to thickness ratio of the tube was smaller than 60 . Han et al. [7] investigated the behavior of square CFT columns, square tubed plain concrete columns and tubed columns using oil to reduce friction coefficient under axial compression. It was found that local buckling of CFT columns occurred earlier and more obviously than that of the tubed columns and that the axial load capacities of square CFT columns were slightly lower than those of square tubed columns. The test results of Zhang et al. [12] showed that the axial compressive strength of square tubed columns was greater than that of square CFT columns when the width to thickness ratio $(D / t)$ of tube was 70 and that the trend reversed when width-to-thickness ratio $D / t<$ 47. Yamamoto et al. [13] demonstrated that the failure mode was not correlated with the cross section dimension, while the confinement effect was related to the cross section dimension and concrete strength. Kwon et al. [14-15] presented an analytical prediction and experimental research for the long term behavior of both circular and square tubed columns and CFT columns. Yu et al. [16] proposed a regression formula to predict the axial resistances of square tubed columns based on the experimental and finite element analysis results. Liu et al. [3] and Qi et al. [17] investigated the axial load behavior of STRC and STSRC stub columns in which the width to thickness varied within the range of 50 and 100, respectively.

The in-filled concrete of square tubed columns is non-uniformly confined and the effectiveness of its confinement is greatly reduced. The system parameters affecting the confinement effect are rather complicated. From the above literature review [7, 10-17], the available research results were focused on tubed plain concrete columns with small dimensions and width-to-thickness ratios $(D / t$ $<100)$. Experimental and theoretical study on large width-to-thickness ratios $(D / t>100)$ tubed reinforce concrete columns are still short. Additionally, significant discrepancies exist between the experimental and theoretical results reported by the researchers. To further clarify the main system 
parameters affecting the axial compressive strength and to develop a unified method to accurately predict the axial load resistances of square stub columns, experimental and theoretical investigations are presented in this paper to demonstrate the composite effect of stub square tubed $\mathrm{RC}$ columns under axial compression.

\section{EXPERIMENTAL PROGRAM}

\subsection{Description of Specimens and Test Set-up}

To investigate the effect of bond and friction on composite response, fourteen stub STRC columns with galvanized and ordinary steel, four stub steel tubed plain concrete columns with and without oil (Mobil DTE 25) which was used to reduce the bond and friction of the interface between ordinary steel tube and concrete, and six reference RC stub columns were tested. The tube was made by welding two cold-formed C-shape steel sections. The surface roughness of galvanized tube is smaller than that of ordinary steel tube. Therefore, the friction coefficient and bond strength between the galvanized tube and concrete are smaller.

Figure 2 depicts the general layout of test specimens. A length to width ratio of 3 was selected for the columns in order to ensure the stub column behavior. Two $10 \mathrm{~mm}$ thick steel endplates were welded at both ends of the column to ensure uniform loading. Two $10 \mathrm{~mm}$ stripes were cut off from the steel tube at $30 \mathrm{~mm}$ away from the both ends of the specimens to avoid carrying loads directly. The details of the specimens and their labeling system of the specimen are shown in Table 1. In the nomenclature of specimen, STRC represents square tubed reinforced concrete specimens; GS represents galvanized steel tube; OS represents ordinary steel tube; STC represents square tubed concrete specimens. As an example, S(GS)-200-1.5-55: S(GS) represents square members with galvanized steel tube; 200 represents outer width $D$ of steel tube; 1.5 represents the nominal thickness of steel tube $(t)$; and 55 represents nominal cubic strength of the concrete. In the STC Group, S-180-3-80 and SU-180-3-80 represent tubed plain concrete columns with and without oil which was used to reduce the bond and friction, respectively.

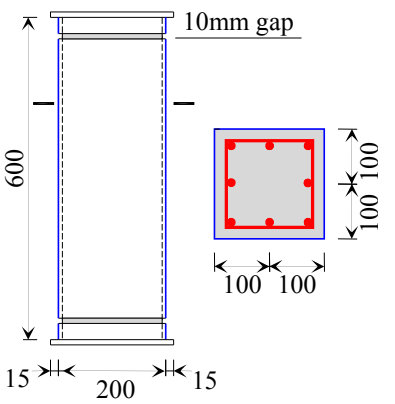

(a) STRC-200

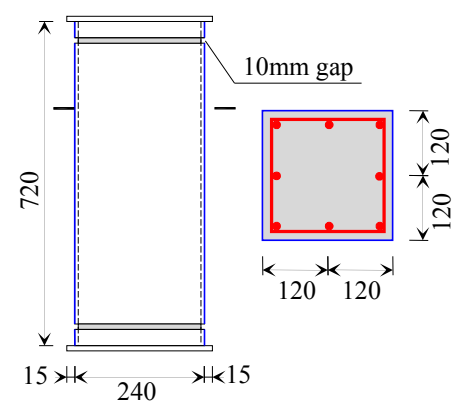

(b) STRC-240

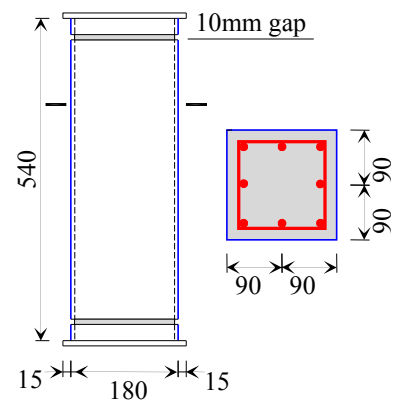

(c) STC-180

Figure 2. The Test Specimens

Table 1. Parameters and Material Strengths of the Test Specimens

\begin{tabular}{|c|c|c|c|c|c|c|c|c|c|c|c|c|c|}
\hline \multirow[b]{2}{*}{ Group } & \multirow[b]{2}{*}{ Specimen } & \multicolumn{5}{|c|}{ Steel tube } & \multirow{2}{*}{$\begin{array}{l}\text { Concrete } \\
f_{\text {co }}(\mathrm{MPa})\end{array}$} & \multirow{2}{*}{\multicolumn{3}{|c|}{$\begin{array}{l}\text { Longitudinal reinforcement } \\
d \\
(\mathrm{~mm})\end{array}$}} & \multicolumn{3}{|c|}{ Stirrup (for erection only) } \\
\hline & & $t(\mathrm{~mm})$ & $D / t$ & $\begin{array}{c}\alpha \\
(\%) \\
\end{array}$ & $f_{\mathrm{y}}(\mathrm{MPa})$ & $\begin{array}{c}f_{\mathrm{u}} \\
(\mathrm{MPa}) \\
\end{array}$ & & & & & $\begin{array}{c}d \\
(\mathrm{~mm})\end{array}$ & spa & $\begin{array}{c}f_{\mathrm{b}} \\
(\mathrm{MPa}) \\
\end{array}$ \\
\hline \multirow{2}{*}{ STRC(GS) } & & & 134 & 3.0 & \multirow{2}{*}{314.0} & \multirow{2}{*}{414.9} & \multirow[b]{2}{*}{ To } & \multirow{2}{*}{19.12} & $\delta \varphi \angle 0$ & \multirow{2}{*}{480.6} & \multirow{2}{*}{8.02} & 0 & \multirow{2}{*}{316.9} \\
\hline & $\mathrm{S}(\mathrm{GS})-240-1.5-55$ & 1.49 & 161 & 2.5 & & & & & $8 \varphi 20$ & & & (a),240 & \\
\hline \multirow{2}{*}{ STRC(OS) } & $\mathrm{S}(\mathrm{OS})-200-1.5-55$ & 1.50 & 133 & 3.0 & \multirow{2}{*}{364.3} & \multirow{2}{*}{449.0} & \multirow{2}{*}{48.1} & \multirow{2}{*}{19.40} & $8 \varphi 20$ & \multirow{2}{*}{477.1} & \multirow{2}{*}{7.82} & (a)200 & \multirow{2}{*}{397.4} \\
\hline & $\mathrm{S}(\mathrm{OS})-240-1.5-55$ & 1.50 & 160 & 2.5 & & & & & $8 \varphi 20$ & & & @,240 & \\
\hline \multirow{2}{*}{ STC } & S-180-3-80 & 3.00 & 60 & 6.7 & 25 & 383.4 & \multirow{2}{*}{59.4} & - & - & - & - & - & - \\
\hline & SU-180-3-80 & 3.00 & 60 & 6.7 & 254.0 & 383.4 & & - & - & - & - & - & - \\
\hline
\end{tabular}


The parameters depicted in the table include the width to thickness ratios of steel tubes $(D / t)$, the steel ratio $\alpha$ (area of steel tube to the gross cross sectional area of specimen) of steel tubes, the yield strength $f_{\mathrm{y}}$ of steel tubes, the ultimate strength $f_{\mathrm{u}}$ of steel tubes, the concrete compressive strength $f_{\text {co }}$ which is determined by prisms with dimensions of $150 \mathrm{~mm} \times 150 \mathrm{~mm} \times 300 \mathrm{~mm}$, the yield strength $f_{\mathrm{a}}$ of longitudinal reinforcement and the yield strength $f_{\mathrm{b}}$ of stirrups. The cubic $(150 \mathrm{~mm} \times 150 \mathrm{~mm} \times 150 \mathrm{~mm})$ strengths of specimens in Groups STRC(GS), STRC(OS) and STC are 56.2 $\mathrm{MPa}, 60.1 \mathrm{MPa}$ and $69.9 \mathrm{MPa}$, respectively. In the following text, for example, S(OS)-200-1 and S(GS)-200-1 are short for S(OS)-200-1.5-55-1 and S(GS)-200-1.5-55-1 respectively. It should be noted that the last numbers "1, 2 or 3 " represents the different specimen with the same dimensions and properties.

The RC counterparts were fabricated by removing the steel tube of Specimens $S(O S)-200-1.5-55$ to ensure the same cured condition with STRC(OS) columns. By doing this, the confining effect of large $D / t$ ratio steel tube could be accurately evaluated. It should be noted that the stirrups of both the STRC and reference RC columns were used to erect the longitudinal reinforcement.

All columns were tested using a $5000 \mathrm{kN}$ hydraulic compression machine (Figure 3). The loading rate was at $1-2 \mathrm{kN} / \mathrm{s}$ in the elastic range. The compressive load was applied slowly and continuously near and after the peak load in order to investigate the softening behavior of the columns.

Four linear variable displacement transducers (LVDTs) were used between the end-plates to monitor the axial deformation. The vertical and transverse strain gauges were arranged on two opposite sides. All the specimens were tested in three batches, and three different arrangements of strain gages were adopted. Firstly, for the STC columns, the vertical and transverse strain gauges were only arranged at the mid-point of mid-height of tubes. Secondly, for STRC(OS) columns, strain gages at the mid-point and corners of mid-height of tubes were added. Furthermore, for STRC(GS) columns, transverse strain gauges were added at the top-end of their steel tubes. The strain gauges at the end of tubes were expected to be in tension because they were close to free ends and did not expect to carry any axial load.
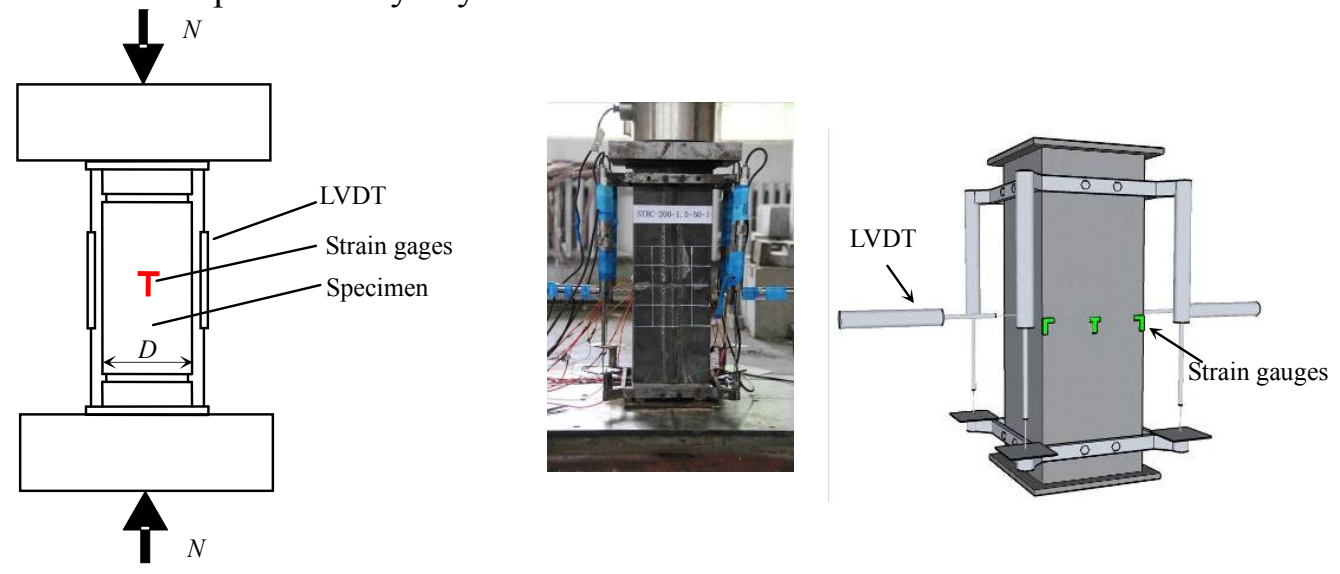

Figure 3. Test Set-up and Instrumentation Layout

\subsection{Failure Patterns and Load-deformation Responses}

Figure 4 depicts failure patterns of the specimens in Groups STRC(GS), STRC(OS) and STC, and also the contrastive RC specimens. The measured axial load versus axial displacement curves of all the tested columns are shown in Figure 5. As for the RC specimen, the concrete cover was spalled off at the peak load and the axial load decreased quickly. The ductility of RC columns was poor (Figures $4 \mathrm{a}-\mathrm{b}$ and 5a). 
The STRC and STC specimens showed similar shear failure patterns in concrete. The shear angles varied from $45^{\circ}$ to $65^{\circ}$ (Figures $4 \mathrm{c}-\mathrm{g}$ ). The core concrete crushed severely due to the buckling of longitudinal rebars. It should be noted that due to the "end effect", a local failure pattern of the core concrete occurred among one of the specimens in Groups S(GS)-200 and S(OS)-240 (Figure 4e). The strength of the two specimens was about $20 \%$ lower compared with other specimens.

Strength and ductility for the contrastive RC columns were improved by steel tubes with large width to thickness ratio $(D / t=133,160)$. The displacement of the STRC specimens increased quickly when loads reached axial load-carrying capacities of the core RC columns (Figures 5a and 5c). STRC(OS) columns had slightly higher axial load-carrying capacities than those of STRC(GS) columns (Figures $5 \mathrm{~b}$ and $5 \mathrm{~d}$ ), and STC columns without reducing friction had slightly higher axial load-carrying capacities than those of STC columns with reduced friction (Figure 5e). It could be concluded that the thin-walled square steel tube could avoid a brittle failure occurring in RC or plain concrete columns with high-strength concrete. Steel tubes with large width to thickness ratio $(D / t=60,133,160)$ could provide moderate confinement effect to RC stub columns.

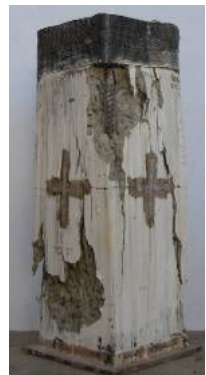

(a) RC-200

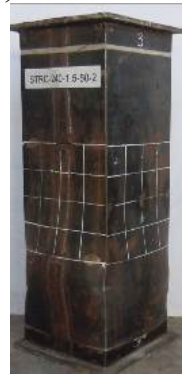

(e) Local failure of S(OS)-240-2
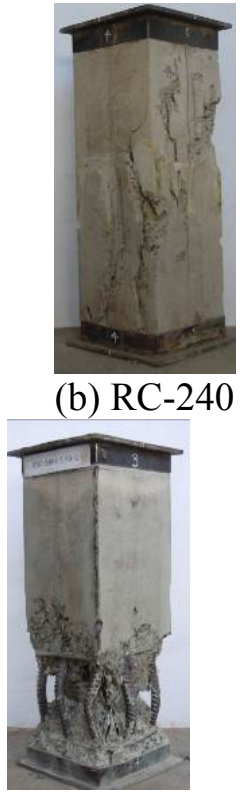

(b) RC-240

Figure 4. Failure Patterns of Columns



(c) $\mathrm{S}(\mathrm{OS})-200$

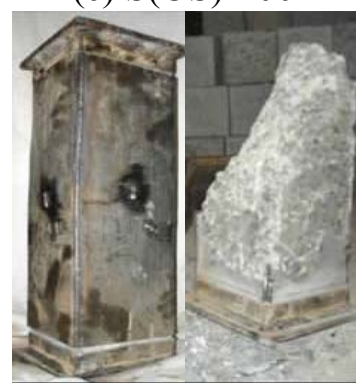

(f) $\mathrm{S}-180-3-80$

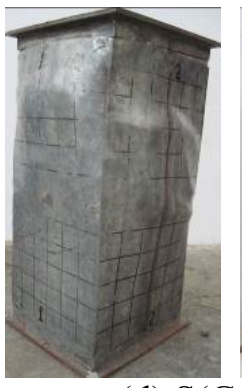

(d) S(GS)-240

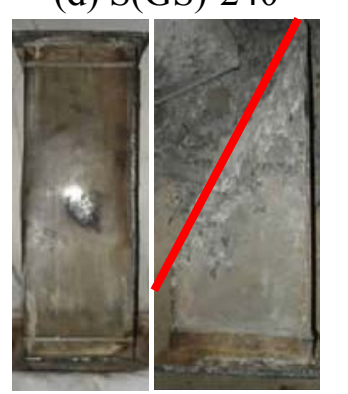

(g) SU-180-3-80

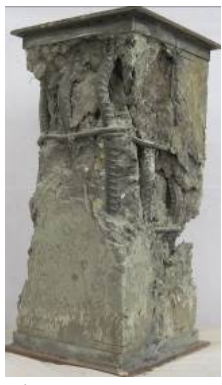






(c) $\mathrm{S}(\mathrm{OS})-240$ and $\mathrm{S} \backslash \mathrm{RC}-240$

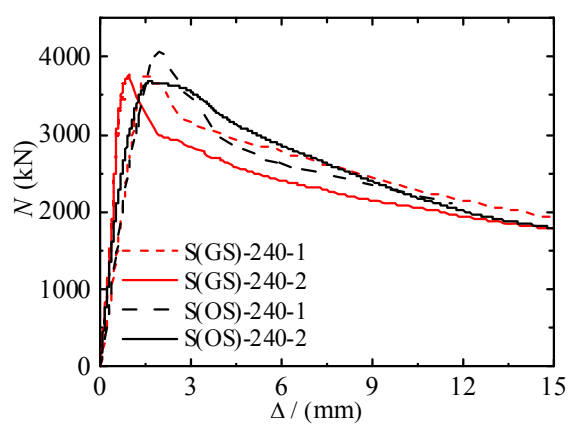

(d) S-240

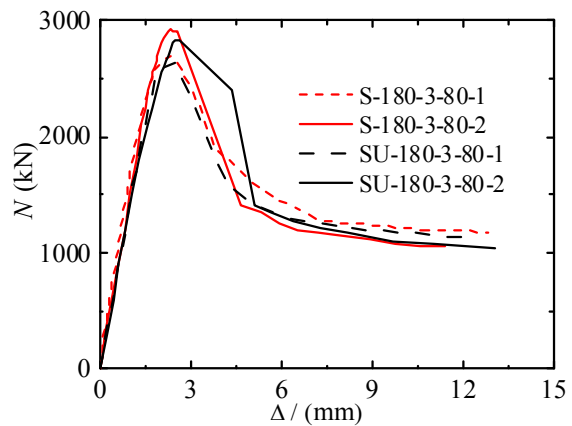

(e) STC

Figure 5. Load-displacement Curves for all the Columns

\subsection{Load-strain/Stress Analysis}

Strain gauges were placed on the two opposite faces of the steel tube to obtain the strain values during the tests (Figure 6). Average values were chosen. The elastic-plastic analysis method (Zhang et al. [18]) was adopted to analyze the stress state in steel tubes based on the measured strains.
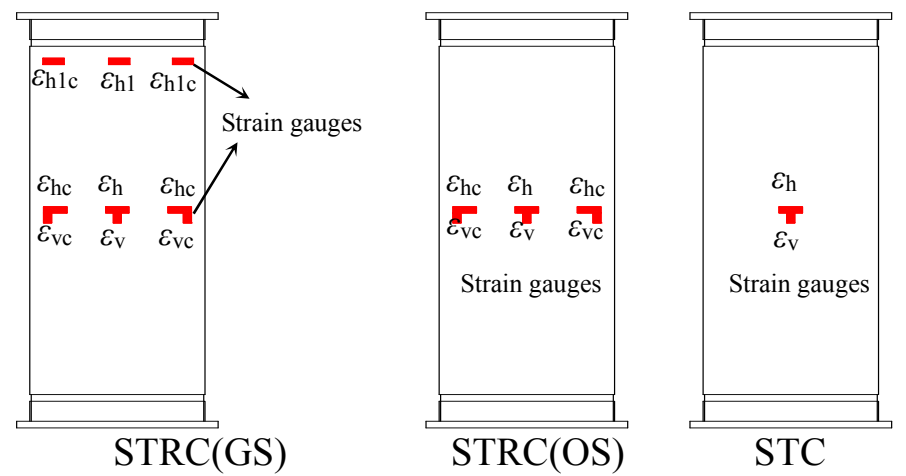

Figure 6. Strain Gauges Arrangement on Steel Tubes

Figure 7 depicts axial load versus strain/stress curves for tubes of representative columns, in which $\sigma_{\mathrm{v}}$ and $\sigma_{\mathrm{h}}$ are respectively longitudinal and transverse stresses at the mid-height of columns and $\sigma_{\mathrm{z}}$ is the equivalent stress. The tension stress $\sigma_{\mathrm{h} 1}$ is the transverse stress at the top-end of the tube. The components of strain and stress at corners are represented with subscript "c". 


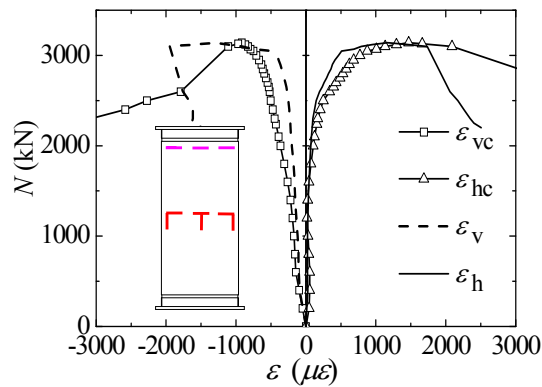

(a1) load-strain curves for mid-height points of S(GS)-200-1

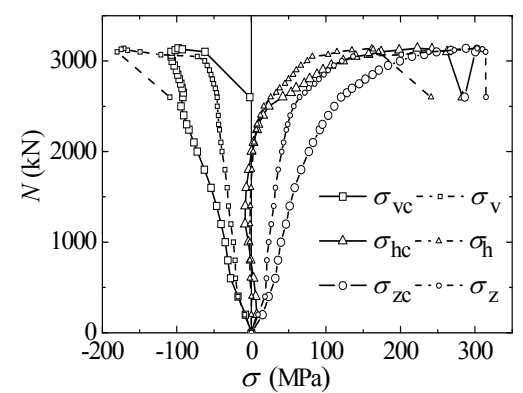

(a2) load-stress curves for mid-height points of S(GS)-200-1

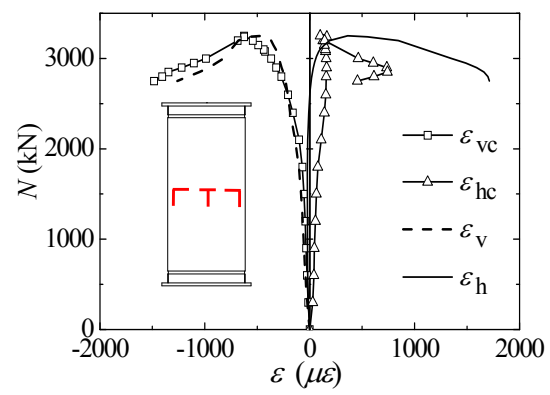

(c1) load-strain curves for mid-height points of S(OS)-200-1

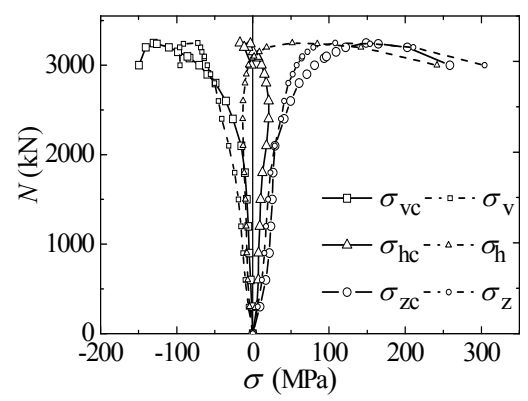

(c2) load-stress curves for mid-height points of S(OS)-200-1

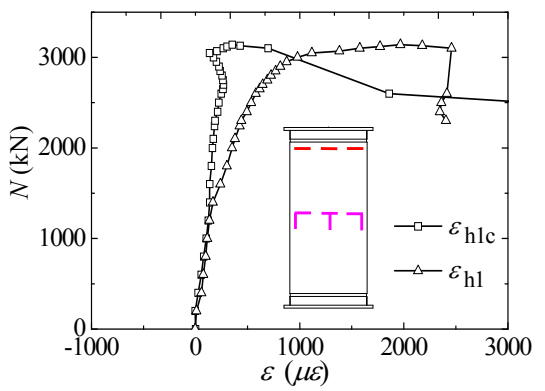

(b1) load-strain curves for top-end points of S(GS)-200-1

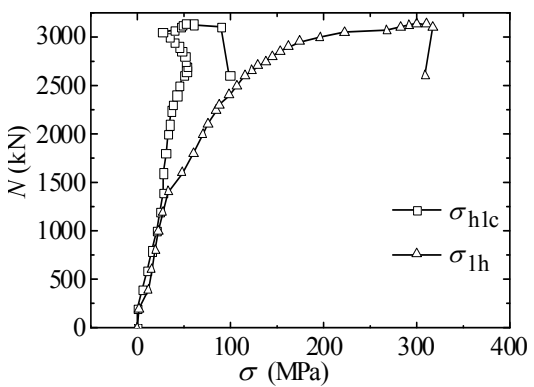

(b2) load-stress curves for top-end points of S(GS)-200-1

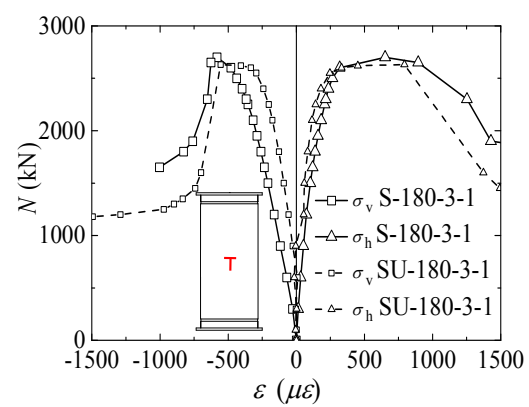

(d1) load-strain curves for mid-height points of STC-180

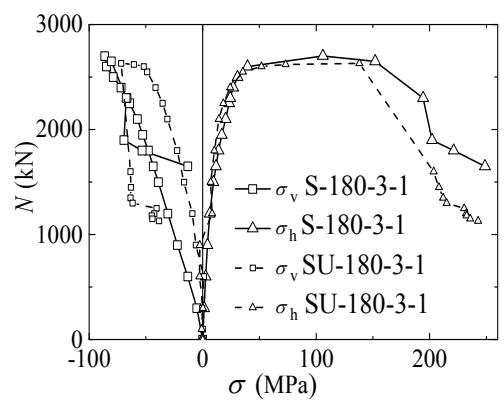

(d2) load-stress curves for mid-height points of STC-180

Figure 7. Load-strain and Load-stress Curves of Steel Tubes

As shown in Figures $7 \mathrm{a}, 7 \mathrm{c}$ and $7 \mathrm{~d}$, both transverse and longitudinal strains/stresses at mid-height of the tube follow a development trend. Taking S(GS)-200-1in Figure 7a as an example, at the elastic stage, the vertical and transverse stresses and strains increase linearly due to the bonding action between concrete and steel tube. The vertical strain and stress increase faster than the transverse ones. When axial loads get close to the resistance of the core RC column, the vertical 
and transverse stresses increase quickly and show a non-linearity feature. At the peak load, the average equivalent stress of the tube does not reach the yield strength, while at least one corner of the tube yields. After the peak load, the vertical and transverse strains keep increasing and the transverse strain and stresses increase faster than the vertical ones. During the testing, the stress components at the corners are higher than those at the middle position for the same load level for STRC columns

Figure $7 \mathrm{~b}$ shows the transverse strain and stress at the top end of tube for STRC(GS) columns. The transverse stress and strain increase with the increase of axial load at the elastic stage and the increase is more obvious at the elastic-plastic stage.

During the testing, the longitudinal stresses of Specimens S-180-3-80 are greater than those of Specimens SU-180-3-80 with reducing friction at the same load level (Figure 7d).

\section{$2.4 \quad$ Experiment Results and Analysis}

Table 2 lists the peak load and stress components of tubes. $N_{\mathrm{u}}$ denotes the peak load. Specimens S(GS)-200-2 and S(OS)-240-2 are not included when computing the average peak load because of local failure. $\sigma_{\mathrm{v}}, \sigma_{\mathrm{h}}$, and $\sigma_{\mathrm{z}}$ are the average stresses of the two opposite plates at the same location.

Table 2. Comparison of Experiment Results at Peak Loads

\begin{tabular}{ccccccccc}
\hline Specimens & $N_{\mathrm{u}}(\mathrm{kN})$ & $\begin{array}{c}\text { Average } \\
\text { value }\end{array}$ & $\sigma_{\mathrm{vc}}(\mathrm{MPa})$ & $\sigma_{\mathrm{hc}}(\mathrm{MPa})$ & $\sigma_{\mathrm{zc}}(\mathrm{MPa})$ & $\sigma_{\mathrm{v}}(\mathrm{MPa})$ & $\sigma_{\mathrm{h}}(\mathrm{MPa})$ & $\sigma_{\mathrm{z}}(\mathrm{MPa})$ \\
\hline $\mathrm{S}(\mathrm{GS})-200-1$ & 3143.2 & \multirow{2}{*}{3143.2} & -98.3 & 222.9 & 287.8 & -171.0 & 161.4 & 302.8 \\
$\mathrm{~S}(\mathrm{GS})-200-2$ & 2623.4 & & -166.1 & -78.0 & 206.8 & 31.9 & 273.3 & 264.6 \\
$\mathrm{~S}(\mathrm{OS})-200-1$ & 3250.2 & & -130.2 & -16.9 & 148.7 & -72.5 & 51.6 & 108.0 \\
$\mathrm{~S}(\mathrm{OS})-200-2$ & 3086.0 & & -97.6 & -67.6 & 258.8 & -146.7 & 113.7 & 230.7 \\
$\mathrm{~S}(\mathrm{OS})-200-3$ & 3381.0 & 3264.0 & -193.9 & -65.7 & 186.2 & -88.0 & 70.1 & 138.7 \\
$\mathrm{~S}(\mathrm{OS})-200-4$ & 3241.3 & & -179.1 & 58.5 & 232.0 & -41.5 & 72.2 & 100.6 \\
$\mathrm{~S}(\mathrm{OS})-200-5$ & 3361.5 & & -108.9 & 125.1 & 204.3 & -103.0 & 104.4 & 180.0 \\
$\mathrm{RC}-200-1$ & 2717.2 & & - & - & - & - & - & - \\
$\mathrm{RC}-200-2$ & 2774.0 & & - & - & - & - & - & - \\
$\mathrm{RC}-200-3$ & 3015.0 & & - & - & - & - & - & - \\
$\mathrm{S}(\mathrm{GS})-240-1$ & 3758.7 & 3758.9 & -35.5 & 220.0 & 219.7 & -12.9 & 268.1 & 274.7 \\
$\mathrm{~S}(\mathrm{GS})-240-2$ & 3759.0 & & -2.7 & 299.4 & 299.4 & -41.4 & 241.4 & 265.4 \\
$\mathrm{~S}(\mathrm{OS})-240-1$ & 4090.5 & & -124.0 & 54.5 & 184.6 & -123.4 & 26.4 & 140.3 \\
$\mathrm{~S}(\mathrm{OS})-240-2$ & 3686.5 & & -183.4 & 80.2 & 242.6 & -132.6 & 66.5 & 177.8 \\
$\mathrm{~S}(\mathrm{OS})-240-3$ & 3872.6 & 3928.9 & -176.1 & 3.6 & 190.3 & -91.4 & 68.1 & 139.1 \\
$\mathrm{~S}(\mathrm{OS})-240-4$ & 3775.8 & & -155.6 & 127.7 & 251.4 & -62.1 & 233.7 & 271.3 \\
$\mathrm{~S}(\mathrm{OS})-240-5$ & 3976.5 & & -181.9 & 101.9 & 251.9 & -94.3 & 79.9 & 152.3 \\
$\mathrm{RC}-240-1$ & 3268.9 & & - & - & - & - & - & - \\
$\mathrm{RC}-240-2$ & 3166.4 & & - & - & - & - & - & - \\
$\mathrm{RC}-240-3$ & 3351.2 & & - & - & - & - & - & - \\
$\mathrm{S}-180-3-80-1$ & 2700.0 & \multirow{2}{*}{2810} & - & - & - & -86.3 & 106.0 & 166.8 \\
$\mathrm{~S}-180-3-80-2$ & 2920.0 & & - & - & - & -78.1 & 120.6 & 173.4 \\
$\mathrm{SU}-180-3-80-1$ & 2630.0 & 2730 & - & - & - & -71.8 & 138.2 & 184.8 \\
$\mathrm{SU}-180-3-80-2$ & 2830.0 & 2730 & - & - & - & -62.3 & 142.8 & 182.1 \\
\hline
\end{tabular}


The average peak load for STC columns without reducing friction is a slightly higher than STC columns with reducing friction. The average peak loads for STRC(OS) columns are slightly higher than those of the STRC(GS). It could be conclude larger friction coefficients correspond to greater axial load-carrying capacities for square tubed columns. However, the peak loads for circular tubed $\mathrm{RC}$ (CTRC) columns with galvanized tube are higher than those of the CTRC columns with ordinary tube although the strengths of concrete and tube are lower than those reported in (Liu et al. [9]). Thus, the effect of friction on the composite response of STRC columns is different from that of CTRC columns.

Because the value of friction coefficient of ordinary tubes is higher than that of galvanized tubes, stress concentration at the tube corners does not fully propagate to middle part. Thus, the equivalent stress of the ordinary tube at corner was larger than that at the middle point, and the equivalent stresses between the middle point and corner of the galvanized tube was close to each other. The longitudinal stresses at the middle point for STC columns without reduced friction is higher than STC columns with reduced friction, but this trend is not visible for transverse stresses. Thus, the stress state at the peak load is influenced by the interface between steel tube and concrete. Larger friction coefficient corresponds to larger longitudinal stresses.

The effect of friction coefficient on stress state and axial load-carrying capacity is further discussed in the following finite element analysis section. At the peak load, at least one corner of the tube yields for almost all specimens, while the average equivalent stress does not reach the yield point due to the uncertainties such as imperfections and loading eccentricity involved in the experiments.

\section{FINITE ELEMENT ANALYSIS (FEA)}

The Damaged Plasticity Model (DPM) for concrete available in ABAQUS (Dassault Systems [19]) was used to analyze the tubed columns subjected to axial compression. A nonlinear finite element (FE) model considering nonlinear material behavior was developed. The FE model was then used to investigate the influence of important system parameters on the ultimate strength of the columns. The steel tube was modelled using 4-node shell elements with reduced integration (S4R). A perfect elastic-plastic model consisting of two distinct loading stages was used to describe the mechanical behavior of the steel. The concrete core was simulated by using 8-node brick elements (C3D8R), with three translation degrees of freedom at each node.

\subsection{Material Properties}

The strength increase and ductility improvement arise from the confinement effect on the concrete. The increased strength can be achieved by defining a yielding surface. The increased peak strain and the even descending branch of stress-strain curve reflect the ductility improvement. A modified concrete stress-strain curve for tubed columns is proposed based on Li et al. [20] (Figure 8).

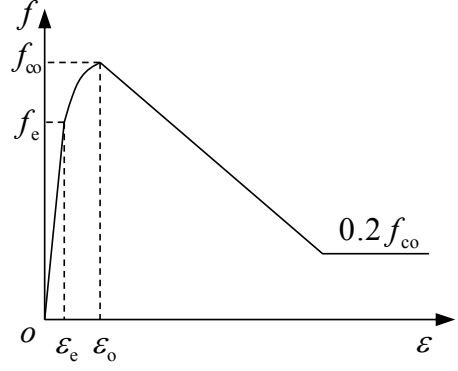

(a) compression

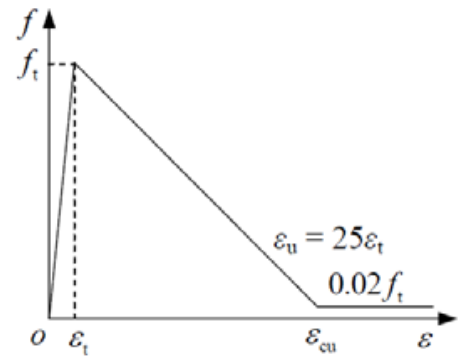

(b) tension

Figure 8. Stress-strain Curves for Concrete 
The compression stress-strain curve for concrete is

$$
f=\left\{\begin{array}{lr}
E_{\mathrm{c}} \varepsilon+\frac{\left(f_{\mathrm{co}}-E_{\mathrm{c}} \varepsilon_{\mathrm{co}}\right)}{\varepsilon_{\mathrm{co}}^{2}} \varepsilon^{2} & 0 \leq \varepsilon \leq \varepsilon_{\mathrm{e}} \\
f_{\mathrm{co}}-\frac{\left(f_{\mathrm{co}}-f_{\mathrm{e}}\right)}{\left(\varepsilon_{\mathrm{o}}-\varepsilon_{\mathrm{e}}\right)^{2}} \times\left(\varepsilon-\varepsilon_{\mathrm{o}}\right)^{2} & \varepsilon_{\mathrm{e}} \leq \varepsilon \leq \varepsilon_{\mathrm{o}} \\
f_{\mathrm{co}}-\beta \frac{f_{\mathrm{co}}}{\varepsilon_{\mathrm{o}}} \times\left(\varepsilon-\varepsilon_{\mathrm{o}}\right) \geq 0.2 f_{\mathrm{co}} & \varepsilon>\varepsilon_{\mathrm{o}}
\end{array}\right.
$$

where

$f_{\text {co }}=$ the compressive strength of concrete,

$E_{\mathrm{c}}=$ the initial Young's modulus of concrete, $E_{\mathrm{c}}=4730 \sqrt{f_{\mathrm{co}}}$,

$\varepsilon_{\mathrm{co}}=$ the strain at maximum strength of unconfined concrete $f_{\mathrm{co}}, \quad \varepsilon_{\mathrm{co}}=\left(700+172 \sqrt{f_{\mathrm{cu}}}\right) \times 10^{-6}$ as given by Guo et al. [21], ( $f_{\mathrm{cu}}$ being the compressive strength for $150 \times 150 \times 150 \mathrm{~mm}$ cubic specimen),

$\varepsilon_{\mathrm{o}}=$ the peak strain of concrete for the FE model, $\varepsilon_{\mathrm{o}}=\varepsilon_{\mathrm{cc}}-\left[\left(\frac{f_{\mathrm{cc}}}{f_{\mathrm{co}}}-1\right)\right] \varepsilon_{\mathrm{co}}$,

$\varepsilon_{\mathrm{cc}}=$ the strain at maximum confined strength of concrete $f_{\mathrm{cc}}, \quad \varepsilon_{\mathrm{cc}}=\left[1+5\left(\frac{f_{\mathrm{cc}}}{f_{\mathrm{co}}}-1\right)\right] \varepsilon_{\mathrm{co}}$ as given by

Mander et al. [22],

$\varepsilon_{\mathrm{e}}=$ the maximum strain for first part of the stress-strain relationships taken as $0.75 \varepsilon_{\mathrm{o}}$ here,

$f_{\mathrm{e}}=$ compressive stress of concrete at the strain $\varepsilon_{\mathrm{e}}$, calculated using Eq. 1, and

$\beta=$ factor to control the slope of the descending branch, $\beta=0.0243\left(\frac{f_{l}}{f_{\text {co }}}\right)^{-0.686} \leq 0.5$.

The compressive strength of confined concrete can be calculated by Eq. 2 (Li et al. [20], Mander et al. [22])

$$
f_{\mathrm{cc}}= \begin{cases}f_{\mathrm{co}}\left(-1.254+2.254 \sqrt{1+7.94 \frac{f_{l}}{f_{\mathrm{co}}}}-2 \frac{f_{l}}{f_{\mathrm{co}}}\right) & f_{\mathrm{co}}<50 \mathrm{MPa} \\ f_{\mathrm{co}}\left(-0.413+1.413 \sqrt{1+11.4 \frac{f_{l}}{f_{\mathrm{co}}}}-2 \frac{f_{l}}{f_{\mathrm{co}}}\right) & 80 \mathrm{MPa} \geq f_{\mathrm{co}} \geq 50 \mathrm{MPa}\end{cases}
$$

where $f_{l}$ is the confining stress of the square tube.

A modified model based on reference [22] was suggested for square tubed columns. As a result, $f_{l}$ is calculated using Eq. 3

$f_{l}=k_{\mathrm{e}} f_{\mathrm{r}}$

where $k_{\mathrm{e}}$ is the confinement effectiveness coefficient for square tubed columns defined by the following equation when the area of longitudinal rebars is ignored

$$
k_{\mathrm{e}}=\frac{A_{\mathrm{e}}}{A}=\left(1-\sum_{i=1}^{n} \frac{\left(D_{\mathrm{i}}\right)^{2}}{6 D_{\mathrm{i}}^{2}}\right)=1 / 3
$$

$f_{\mathrm{r}}$ is the lateral pressure from the tube assumed to be uniformly distributed over the surface of the concrete core, which is equal to the lateral pressure provided by the circumcircle of the square tube (Figure 9), i.e.

$$
f_{\mathrm{r}}=2 \frac{t f_{\mathrm{y}}}{\sqrt{2} D-2 t}
$$






(a) Effectively confined cross section

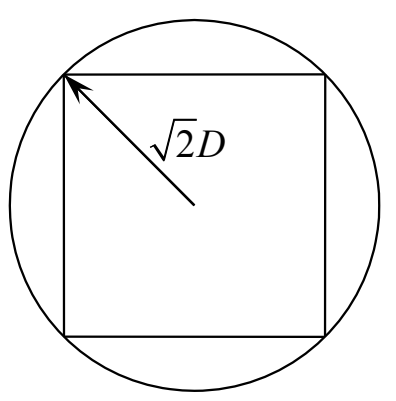

(b) Lateral pressure $f_{\mathrm{r}}$ provided by the circumcircle of a square section

Figure 9. Effective Confinement Model for Square Tubed Columns

For concrete in tension, a simplified stress-strain relationship was used in the analysis, in which $f_{\mathrm{t}}$ and $\varepsilon_{\mathrm{t}}$ are the tensile strength and the strain at the tensile strength of concrete respectively, and $\varepsilon_{\mathrm{cu}}$ is the ultimate strain of concrete in tension taken as $25 \varepsilon_{\mathrm{t}}$ here. The empirical expressions for defining $f_{\mathrm{t}}$ and $\varepsilon_{\mathrm{t}}$ are [21]

$$
\begin{gathered}
f_{\mathrm{t}}=0.26 f_{\mathrm{cu}}^{2 / 3} \\
\varepsilon_{\mathrm{t}}=65 \times 10^{-6} f_{\mathrm{t}}^{0.54}
\end{gathered}
$$

In the DPM for concrete, the dilation angle $\Psi=38^{\circ}$ was suggested. $K_{\mathrm{c}}$ was defined as $K_{\mathrm{c}}=\left(\sqrt{J_{2}}\right)_{\mathrm{TM}} /\left(\sqrt{J_{2}}\right)_{\mathrm{CM}}$, where $0.5<K_{\mathrm{c}} \leq 1$ and TM and CM designate respectively the "tensile meridian" and the "compressive meridian" on the yield surface. $K_{\mathrm{c}}=0.67$ was suggested for square tube confined concrete [19].

\subsection{Effect of Friction}

Friction is an important factor which influences the composite response of tubed columns as the bond is likely broken during a test. A surface-based interaction with a contact pressure model in the normal direction and a Coulomb friction model in the tangential direction to the surface between steel tube and core concrete (Han et al. [23]) was used in the finite element analysis (FEA). The interface elements consist of two matching contact faces of steel tube and concrete elements. The friction coefficient $\mu$ between steel and concrete suggested by Rabbat et al. [24], Baltay et al. [25] and Aly et al. [26] is within the range of $0.2 \sim 0.65$. Therefore, $\mu=0.2$ was used for galvanized tubes and $\mu=0.6$ was employed for ordinary tubes. Figure 10 depicts the FEA results for specimens S(OS)-200 and S(GS)-200. The analysis results agree well with the experimental ones. The finite element method and the suggested values for the parameters could also accurately predict the behavior of circular tubed columns (Liu et al. [9]). 


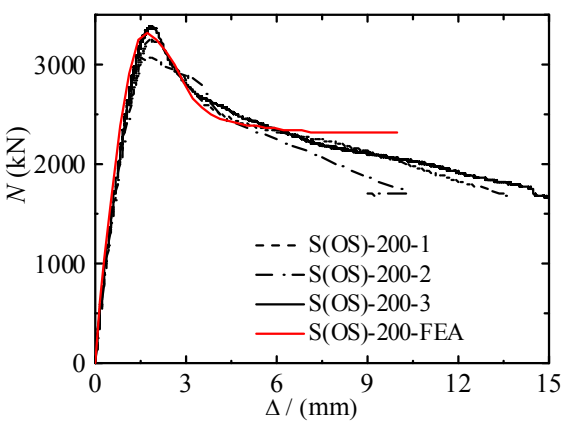

(a) STRC(OS)-200

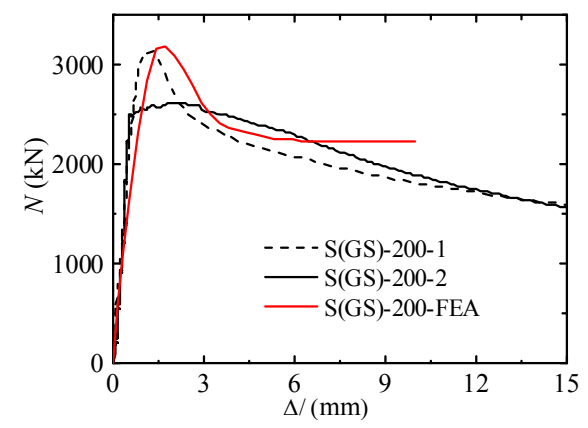

(b) STRC(GS)-200

Figure 10. Comparison of Load $(N)$-axial Displacement $(\Delta)$ Curves between Test and FEA Results

To investigate the mechanisms of square tubed columns (STC) subjected to axial load, square tubed columns (STCs) were designed first to study the effect of friction coefficient in ABAQUS. All parameters maintained at constant values except the friction coefficient $\mu$ changed from 0 to 1.0. The parameters and analysis results are summarized in Table 3. Figure 11 shows the FE model and von Mises stress components for specimen with $\mu=0.6$, in which the corners of tube yield at the peak load. The FEA results agree well with the experimental ones. The analysis results also show that the specimen with larger friction coefficient yields higher axial load strength. Thus, it is deduced that the square tube is more beneficial to direct bearing of axial loads than concrete confining if it does not buckle. The effectiveness of confinement for square tube is significantly reduced implying that the square tube cannot be fully utilized. This explains that the axial strength of square tubed columns is greater than that of square CFT columns when the width to thickness ratio $(D / t)$ of tube is around 70 and the trend reverses when $D / t<47$ as reported by Zhang et al. [12]. In order to provide sufficient confinement to concrete core and longitudinal reinforcement, $D / t$ ratio should be limited or a stiffening arrangement should be made for square thin-walled tubes. The strength is little affected when the friction coefficient exceeds 0.6.

Table 3. Effect of the Friction Coefficient on Resistances of STC Specimens

\begin{tabular}{|c|c|c|c|c|c|c|}
\hline$D(\mathrm{~mm})$ & $t(\mathrm{~mm})$ & $f_{\mathrm{y}}(\mathrm{MPa})$ & $f_{\mathrm{co}}(\mathrm{MPa})$ & $\mu$ & Peak load( & omparisons \\
\hline \multirow{6}{*}{200} & \multirow{6}{*}{1.5} & \multirow{6}{*}{310} & \multirow{6}{*}{38.0} & 0 & 1613.7 & $100.0 \%$ \\
\hline & & & & 0.2 & 1649.9 & $102.2 \%$ \\
\hline & & & & 0.4 & 1673.7 & $103.7 \%$ \\
\hline & & & & 0.6 & 1687.5 & $104.6 \%$ \\
\hline & & & & 0.8 & 1693.0 & $104.9 \%$ \\
\hline & & & & 1.0 & 1693.9 & $105.0 \%$ \\
\hline
\end{tabular}
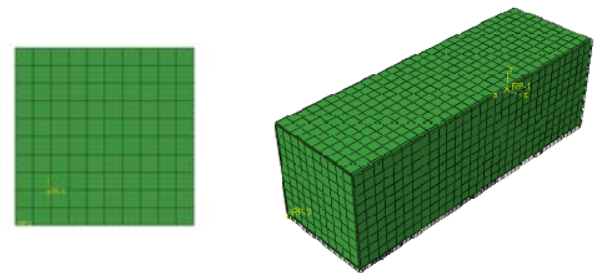

(a) Model for STC-200
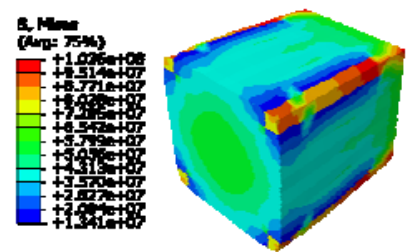

(b) Equivalent stress for concrete (Half model)

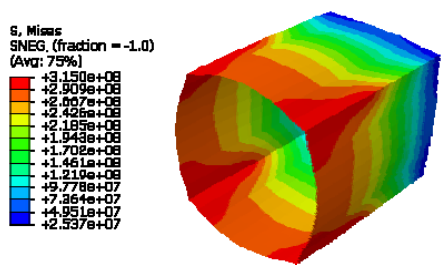

(c) von Mises stress for tube of STC-200

Figure 11. FE Modal and Analysis Results of STC-200 


\subsection{Effect of the Chamfered Corner Radius}

The out-of-plane flexural stiffness of thin-walled tubes is small. Therefore, the tubes provide little confinement pressure by flexure. The confinement effect of square tubes is mainly provided by the arch action at the corners. As such, stress concentration occurs at the corners. The larger the corner radius is, the greater the confinement effect. The square tube changes into a circular one when the corner radius equals to half width dimension. A group of square tubed columns were designed to study the effect of corner radii in ABAQUS. Table 4 lists the dimension, material property, and analysis results, in which S-200 points to a sharp corner and S-200-5mm represents a specimen with $5 \mathrm{~mm}$ corner radius. It was found the axial load-carrying capacity of specimen S-200-5mm was $11.6 \%$ larger compared to specimen S-200. The axial load-carrying capacities of STRC(OS)-200 specimen with $2 \mathrm{~mm}$ and $5 \mathrm{~mm}$ are $5.8 \%$ and $6.8 \%$ larger compared to the specimen with sharp corner radius, respectively. The increasing percentages are smaller because of a higher axial load-carrying capacity due to longitudinal rebars. Figure 12 depicts the load-displacement curves. The whole cross section of tube yields for Specimen S-200-5mm, while only the corners of tube yield for specimen S-200 (Figure 13). Chamfered corners can effectively improve the confinement effect of square tubes.

Table 4. Axial Compression Capacities of Specimens with Sharp and Chamfered Corners

\begin{tabular}{cccccccc}
\hline Specimens & $\begin{array}{c}\text { Width } D \\
(\mathrm{~mm})\end{array}$ & $\begin{array}{c}t \\
(\mathrm{~mm})\end{array}$ & $\begin{array}{c}f_{\mathrm{y}} \\
(\mathrm{MPa})\end{array}$ & $\begin{array}{c}f_{\mathrm{co}} \\
(\mathrm{MPa})\end{array}$ & $\mu$ & $\begin{array}{c}\text { Peak load } \\
(\mathrm{kN})\end{array}$ & $\begin{array}{c}\text { Increasing } \\
\text { percentage }\end{array}$ \\
\hline S-200 & \multirow{2}{*}{200} & \multirow{2}{*}{1.5} & \multirow{2}{*}{315.0} & 47.4 & 0.6 & 1991.7 & 0 \\
S-200-5mm & & & & & & 2230.0 & $11.6 \%$ \\
\hline STRC(OS)-200-sharp & \multirow{2}{*}{200} & \multirow{2}{*}{1.5} & \multirow{2}{*}{364.3} & \multirow{2}{*}{48.1} & \multirow{2}{*}{0.6} & 3321.8 & 3513.7 \\
STRC(OS)-200-2mm & & & & & & 3546.8 & $\begin{array}{c}5.8 \% \\
\text { STRC(OS)-200-5mm }\end{array}$ \\
\hline
\end{tabular}

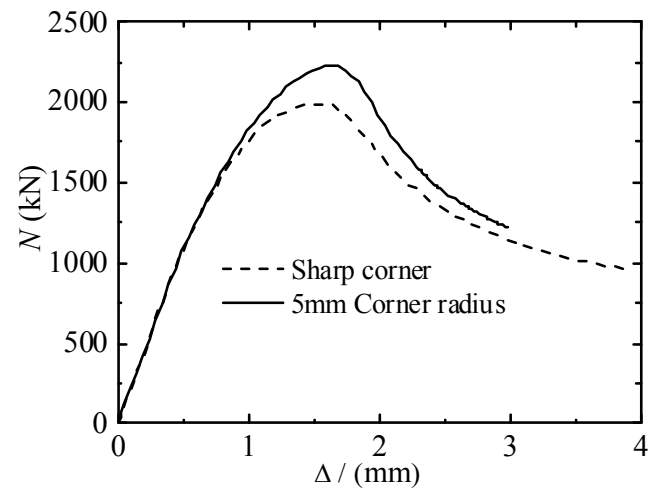

Figure 12. Load-displacement Curves for the Specimens with Sharp Corners and 5mm Corner Radius

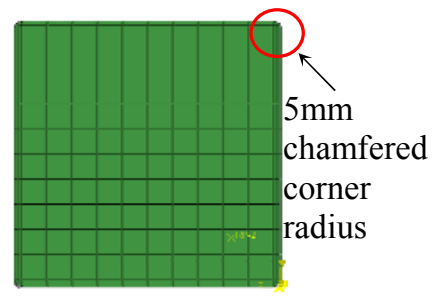

Model for S-200-5mm
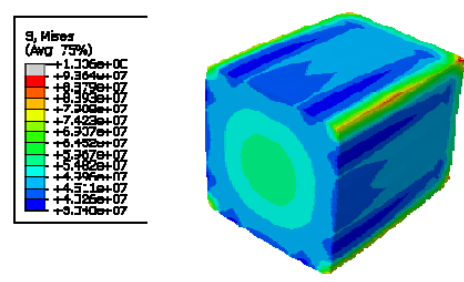

Equivalent stress for concrete (a) S-200-5mm
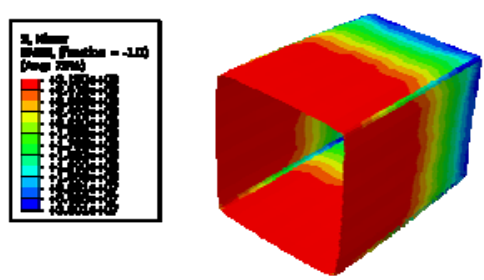

von Mises stress for the tube 


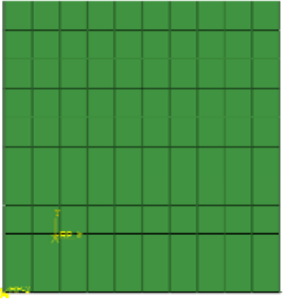

Model for S-200

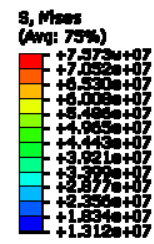

Equivalent stress for concrete

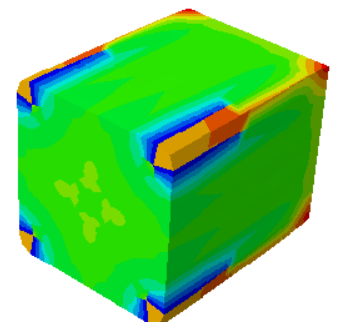

(b) S-200

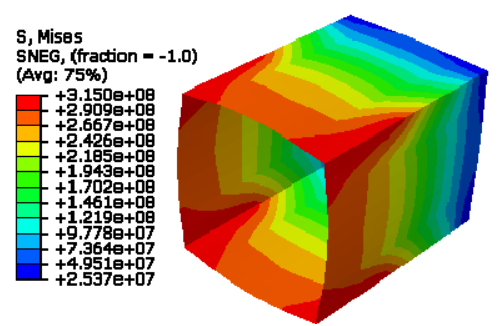

von Mises stress for the tube

Figure 13. FEA Model and Stress Analysis Results for S-200-5mm and S-200 at Peak Load

The selection of $5 \mathrm{~mm}$ represents a typical corner radius of cold-formed square tube being welded at the middle of the plate, as also referenced in (Liu et al. [3], Qi et al. [17]). In the tests done by Sakino et al. [10-11] and Yamamoto et al. [13], the square tubes were welded at the sharp corners. In this study, the corner radius of specimens was about $2 \mathrm{~mm}$ based on the measurement of the tube. The peak loads predicted by the FEA for specimen STRC(OS)-200 are $3321.8 \mathrm{kN}$ (sharp corners), $3513.7 \mathrm{kN}$ ( $2 \mathrm{~mm}$ corner radius) and $3546.8 \mathrm{kN}$ (5mm corner radius). The FEA results offer the explanation why there is discrepancy between experimental and theoretical results reported in references. Cold-formed steel tubes are recommended in practice because of better structural behavior due to chamfered corners when square cross sectional columns are used.

\section{AXIAL LOAD-CARRYING CAPACITIES OF STUB SQAURE TUBED COLUMNS}

Based on the experimental and numerical researches, the difference of axial load-carrying capacities between specimens with different tube or different friction is within $5 \%$, as shown in Table 2 and Table 3. Simply considering the tube as an element to confine the concrete will result in a conservative axial compressive strength.

The axial load-carrying capacity can be determined by

$$
N_{\mathrm{u}}=f_{\mathrm{cc}} A_{\mathrm{c}}+f_{\mathrm{a}} A_{\mathrm{a}}
$$

where $A_{\mathrm{c}}$ and $A_{\mathrm{a}}$ are the cross-sectional area of concrete and longitudinal reinforcement (structural steel), respectively; $f_{\mathrm{a}}$ is the yield strength of longitudinal reinforcement or structural steel; $f_{\mathrm{cc}}$ is the compressive strength of confined concrete.

A modified model based on the effective confinement area method for square stirrups confined concrete (Mander et al. [22]) which has been widely accepted was suggested to compute $f_{\text {cc }}$ of square tubed columns. In practice, the average stress at the corners does not yield at the peak load due to initial imperfection of the columns and experimental uncertainties, while at least one corner yields for almost all specimens as shown in the previous tests. Thus, an effective utilization index $k_{\mathrm{t}}$ was adopted to account for the non-uniform stress distribution on the tube. $k$ is defined as the ratio of the average stress of the corners to the yield strength of tube. $k \mathrm{t}$ can be taken as 0.8 based on the experimental results. The effective lateral confining pressure $f_{\mathrm{r}}^{\prime}$ can be calculated by

$$
f_{\mathrm{r}}^{\prime}=k_{\mathrm{t}} f_{l}=k_{\mathrm{e}} k_{\mathrm{t}} f_{\mathrm{r}}
$$


$k_{\mathrm{e}}$ is given by Eq. 4 . The confined compressive strength $f_{\mathrm{cc}}$ can be computed by substituting $f_{\mathrm{r}}^{\prime}$ into Eq. 2.

A total of 124 experimental axial strength values for tubed columns were collected from (Liu et al. [3], Han et al. [8], Sakino et al. [10-11], Zhang et al. [12], Yamamoto et al. [13], and Qi et al. [17]). The considered test parameters for the experimental results include width to tube thickness ratio $D / t$ (20-162), concrete strength (28.5-132 MPa), and longitudinal reinforce ratio (0-6.5\%). The results predicted by Eq. 8 agree well with the experimental results (Figure 14). The average ratio of predicted axial strength to experimental axial strength is 0.92 . The root-mean-square deviation is 0.14 and the correlation coefficient is 0.94 .

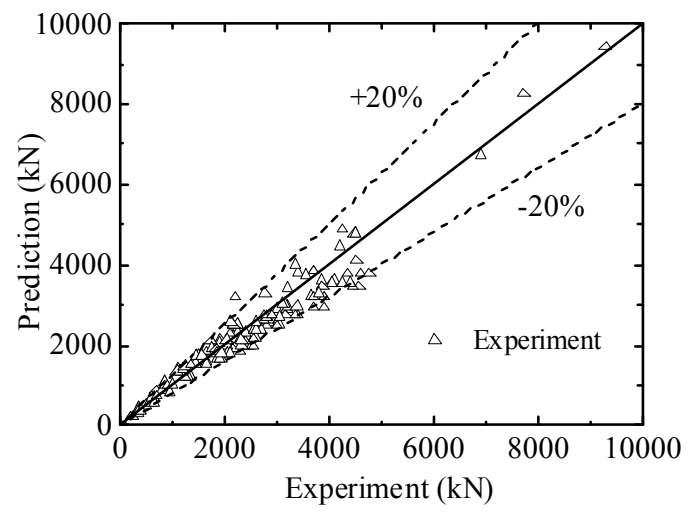

Figure 14. Comparisons between Eq. 8 and the test results

\section{SUMMARY AND CONCLUSIONS}

This paper describes and discusses the structural behavior of square tubed columns under axial compression experimentally, analytically, and numerically. Based on this study, the following conclusions are offered.

(1) The types of the interface between the tube and concrete cannot influence on the failure modes of the square tubed columns. Shear failure of core concrete occurred in square tubed columns with width-to-thickness ratios of 60-160. Strength and ductility of the contrasting RC columns can be improved by using the tube with large width-to-thickness ratios of 133-160.

(2) For both galvanized and ordinary tubes, the average stress at the corner of the tubes did not yield at the peak load, while at least one corner yielded for almost all the specimens. Larger friction coefficient corresponds to larger longitudinal stresses and slightly larger axial compressive strength.

(3) The predicted results from the nonlinear finite element analysis are in good agreement with the test results. The greater the corner radius is, the larger the axial load capacity. Axial load-carrying capacities between different friction coefficients varied within $5 \%$. There is no need to eliminate the bond and friction effect in practice. Cold-formed steel tubes are recommended in practice because of better structural behavior due to chamfered corners.

(4) A simplified effective confinement model, simply and conservatively considering tubes as elements to confine in-filled concrete together with the effective utilization of square tubes, was proposed to predict axial load-carrying capacities. The predicted results are in good agreement with experimental results. 


\section{ACKNOWLEDGEMENT}

The authors greatly appreciate the financial supports provided by the National Natural Science Foundation of China (No. 51308051 \& 51438001), Chongqing Research Program of Basic Research and Frontier Technology (No. cstc2016jcyjA0284) and the China Scholarship Council. The opinions expressed in this paper are solely of the authors, however.

\section{REFFERENCES}

[1] Kang, W.H., Uy, B., Tao, Z. and Hicks, S., "Design Strength of Concrete-filled Steel Columns", Advanced Steel Construction, 2015, Vol. 11, No. 2, pp. 165-184.

[2] Liu, S.W., Liu, Y.P. and Chan, S.L., "Advanced Analysis of Hybrid Steel and Concrete Frames: Part 1: Cross-section Analysis Technique and Second-order Analysis", Jounral of Constructional Steel Research, 2012, Vol. 70, pp. 326-336.

[3] Liu, J.P. and Zhou, X.H., "Behavior and Strength of Tubed RC Stub Columns under Axial Compression", Journal of Constructional Steel Research, 2010, Vol. 66, No. 1, pp. 28-36.

[4] Gan, D., Zhou, X.H., Yan, B., Han, F.L. and Liu, J.P., "Experimental Studies on Structural Behavior of Circular Tubed Reinforced Concrete Joints with Ring Ribs", Journa of Building Structures, 2018, Vol. 39, No. 4, pp. 91-101. (In Chinese)

[5] Sakino, K., Tomii, M. and Watanabe, K., "Sustaining Load Capacity of Plain Concrete Stub Columns Confined by Circular Steel Tube", Proceeding of the International Speciality Conference on Concrete Filled Steel Tubular Structures, Harbin, China, 1985, pp.112-118.

[6] Orito, Y., Sato, T., Tanaka, N. and Watanabe, Y., "Study on the Unbonded Steel Tube Composite System", Proceedings, Composite Construction in Steel and Concrete, Engineering Foundation, 1987, pp. 786-804.

[7] Fam, A., Qie, F.S. and Rizkalla, S., "Concrete-Filled Steel Tubes Subjected to Axial Compression and Lateral Cyclic Loads", Journal of Structural Engineering, 2004, Vol. 125, No. 5, pp.631-640.

[8] Han, L.H., Yao, G.H., Chen, Z.P. and Yu, Q., "Experimental Behaviour of Steel Tube Confined Concrete (STCC) Columns", Steel and Composite Structures, 2005, Vol. 5, No. 6, pp. 459-484.

[9] Liu, J.P., Zhou, X.H. and Gan, D., "Effect of Friction on Axially Loaded Stub Circular Tubed Columns", Advances in Structural Engineering, 2016, Vol. 19, No. 3, pp. 546-59.

[10] Sakino, K. and Sun, Y.P., "Stress-strain Curve of Concrete Confined by Rectilinear Hoop", Journal of Structural and Constructional Engineering, 1994, No. 461, pp. 95-104.

[11] Sakino, K. and Sun, Y.P., "Steel Jacketing for Improvement of Column Strength and Ductility", 12th World Conference on Earthquake Engineering, Auckland, New Zealand, 2000, pp. 2525-40.

[12] Zhang, S.M. and Liu, J.P., "Seismic Behavior and Strength of Square Tube Confined Reinforced-concrete", Journal of Constructional Steel Research, 2007, Vol. 63, No. 9, pp. 1194-1207.

[13] Yamamoto, T., Kawaguchi, J. and Morino, S., "Experimental Study of Scale Effects on the Compressive Behavior of Short Concrete-Filled Steel Tube Columns", Composite Construction in Steel and Concrete IV Proceedings of the Fourth International Conference on Composite Construction in Steel and Concrete, ASCE Conf. Proc., 2000, pp. 879- 890.

[14] Kwon, S.H., Kim, Y.Y. and Kim, J.K., "Long-term Behavior under Axial Service Loads of Circular Columns made from Concrete Filled Steel Tubes", Magazine of Concrete Research, 2005, Vol. 57, No. 2, pp. 87-99. 
[15] Kwon, S.H., Kim, T.H. and Kim, Y.Y., "Long-term Behavior of Square Concrete Filled Tubular Columns under Axial Service Loads", Magazine of Concrete Research, 2007, Vol. 59, No. 1, pp. 53-69.

[16] Yu, Q., Tao, Z. and Liu, W., "Analysis and Calculations of Steel Tube Confined Concrete (STCC) Stub Columns", Journal of Constructional Steel Research, 2010, Vol. 66, No. 1, pp. 53-64.

[17] Qi, H.T., Guo, L.H., Liu, J.P. and Gan, D., "Axial Load Behavior and Strength of Tubed Steel Reinforced-concrete (SRC) Stub Columns”, Thin-Walled Structures, 2011, Vol. 49, No. 9, pp. 1141-1150.

[18] Zhang, S.M., Guo, L.H. and Ye, Z.L., "Behavior of Steel Tube and Confined Concrete High Strength Concrete for Concrete-filled RHS Tubes", Advances in Structural Engineering, 2008, Vol. 8, No. 5, pp. 101-116.

[19] ABAQUS Version 6.8-1, "User Documentation", Dassault Systems, 2008.

[20] Li, B., Park, R. and Tanaka, H., "Stress-strain Behavior of High-strength Concrete Confined by Ultra-high and", ACI Structural Journal, 2001, Vol. 98, No. 3, pp. 395-406.

[21] Guo, Z.H. and Shi, X.D., "Reinforced Concrete Theory and Analyses. Beijing, China: Tsinghua University Press", 2003. [in Chinese].

[22] Mander, J.B., Priestley, M.J.N. and Park, R., "Theoretical Stress-strain Model for Confined Concrete", Journal of Structural Engineering, 1988, Vol. 114, No. 8, pp. 1804-1826.

[23] Han, L.H., Yao, G.H. and Tao, Z., "Performance of Concrete-filled Thin-walled Steel Tubes under Pure Torsion", Thin-Walled Structures, 2007, Vol. 45, No. 1, pp. 24-36.

[24] Rabbat, B.G. and Russell, H.G., "Friction Coefficient of Steel on Concrete or Grout", Journal of Structural Engineering, 1985, Vol. 111, No. 3, pp. 505-515.

[25] Baltay, P. and Gjelsvik, A., "Coefficient of Friction for Steel on Concrete at High Normal Stress", Journal of Materials in Civil Engineering, 1990, Vol. 2, No. 1, pp. 46-49.

[26] Aly, T., Eichalakani, M. and Thayalan, P., "Incremental Collapse Threshold for Pushout Resistance of Circular Concrete Filled Steel Tubular Columns", Journal of Constructional Steel Research, 2010, Vol. 66, No. 1, pp. 11-18. 